\title{
Physicochemical Characterisation of Technical Lignins for Their Potential Valorisation
}

\author{
Omar Y. Abdelaziz ${ }^{1}$. Christian P. Hulteberg ${ }^{1}$ (i)
}

Received: 24 March 2016/Accepted: 25 July 2016/Published online: 1 August 2016

(c) The Author(s) 2016. This article is published with open access at Springerlink.com

\begin{abstract}
Lignin, the second most abundant natural polymer, has emerged as a potential alternative material to petroleum-based chemicals and renewable resource for the production of diverse forms of aromatics, biofuels, and biobased materials. Thus, it is becoming important to understand its structure and properties to provide key features and insights for better/efficient lignin valorisation. In this work, the physicochemical characterisation of two types of industrial (technical) lignins, namely LignoBoost lignin and alkali-treated lignin was performed. Characterisation has been conducted using Brunauer-Emmett-Teller $\mathrm{N}_{2}$ adsorption, particle size distribution, Fourier transform infrared spectroscopy, ultraviolet-visible absorption spectroscopy, gel permeation chromatography, and thermogravimetric analysis. It was found that the pretreatment severity considerably influenced the lignin composition and functional properties. The measured physicochemical properties helped in proposing potential valorisation routes for these lignins in the context of a biorefinery, focusing on their depolymerisation and subsequent biological conversion to value-added chemicals and fuels.
\end{abstract}

Keywords Lignin - Structural characterisation · Physicochemical properties - LignoBoost - Soda pulping · Biomass valorisation

Christian P. Hulteberg

Christian.Hulteberg@ chemeng.lth.se

1 Department of Chemical Engineering, Lund University, P.O. Box 124, 22100 Lund, Sweden

\section{Introduction}

Lignin is a complex biopolymer of phenylpropanoid subunits that accounts for approximately $15-35 \%$ of the terrestrial lignocellulosic biomass, representing the most abundant renewable phenolic polymer on Earth and providing structural integrity to lignocellulosic material. It is expected that in the near future, the advent of new biorefineries, which convert cellulosic biomass into transportation biofuels, will introduce an excess supply of various lignins into the process streams, besides the substantial amounts of lignin produced annually from pulping [1]. This turns lignin into a potentially highly available and accessible renewable feedstock for the synthesis of bulk aromatic and phenolic compounds [2]. Also, in comparison with cellulose and hemicellulose, lignin carries the highest specific energy content within the organic matrix of woody materials [3]. Thus, it can be regarded as an attractive constituent of woody biomass for the production of advanced biofuels and value-added chemicals that can consequently help in meeting the future energy demands [4].

Lignin structure (Fig. 1a), content, and reactivity vary from one substrate to another, as they differ according to the origin and separation/pretreatment methods, generating a wide diversity of lignin aromatic biopolymers. The main building blocks of lignin are guaiacyl $(\mathrm{G})$, syringyl (S), and $p$-hydroxyphenyl $(\mathrm{H})$ that are produced throughout the dehydrogenative enzyme-initiated free-radical polymerisation of the monolignols (Fig. 1b) or so-called the major precursors [5]. Softwood lignins are predominantly formed from coniferyl alcohol and consist of $\mathrm{G}$ units. On the other hand, hardwood lignins constitute both coniferyl and sinapyl alcohol as monomer precursors and contain G, S, and $\mathrm{H}$ units in different ratios. Coniferyl, sinapyl, and 


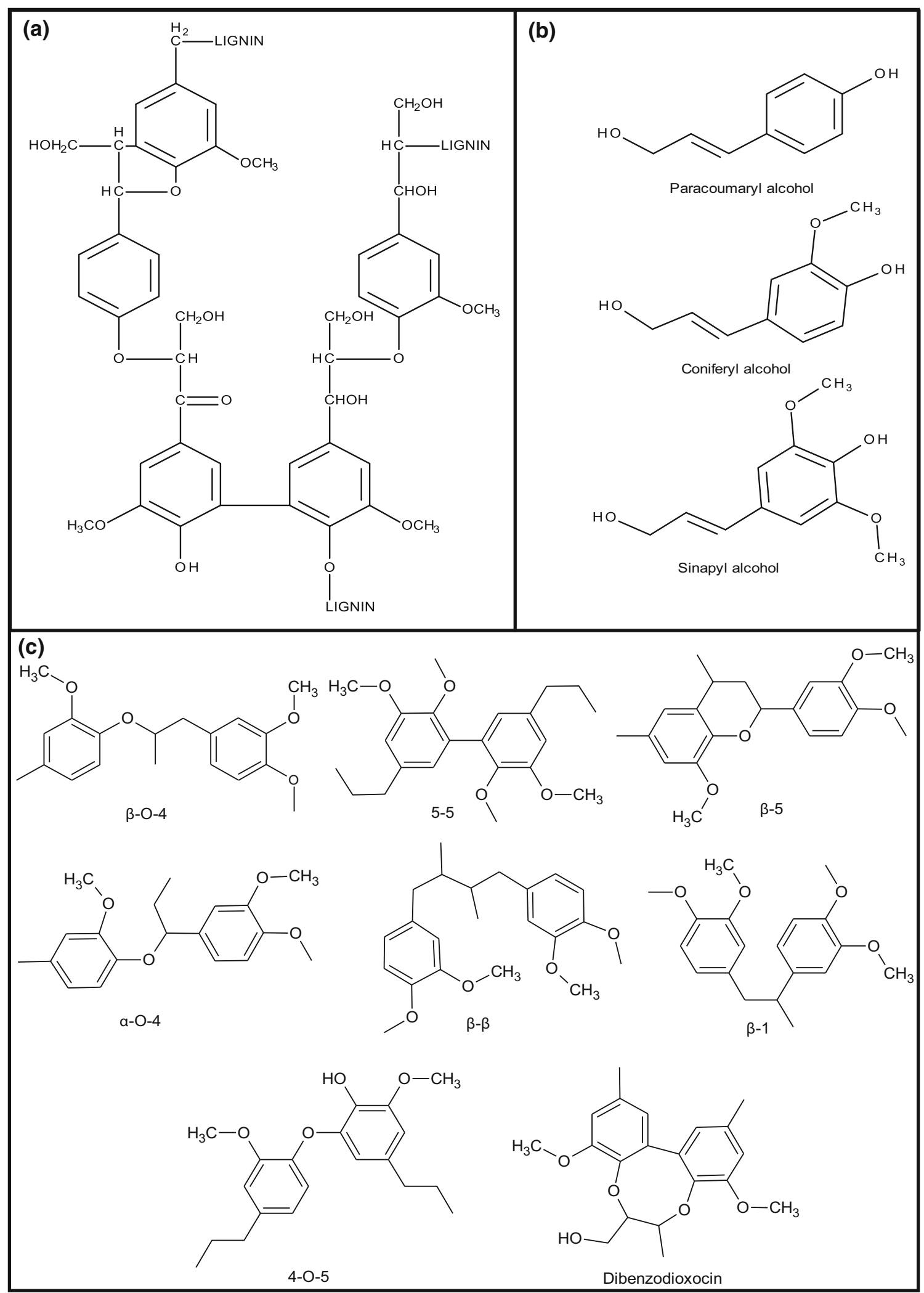

Fig. 1 Lignin, representative fragment (a), three major precursors (b), and common interunit linkages found in its structure (c) 
coumaryl alcohol form the herbaceous (grass) lignins, where they also contain $\mathrm{G}, \mathrm{S}$, and $\mathrm{H}$ [6]. These structures are heterogeneously connected by interunit linkages that provide the biomass with inherent recalcitrance. The linkages (Fig. 1c) include $5-5, \beta-5, \alpha-O-4, \beta-\beta, \beta-1,4-O-5$, dibenzodioxocin, and $\beta-O-4$ aryl glycerol ether which is considered dominant by constituting more than half of the lignin linkage structures [7].

The pulp and paper industry is now considered the largest prevailing lignocellulosic-based process that produces significant amount of lignin. Primarily, chemical pulping processes are used for producing paper and celluloses derivatives [8]. Kraft pulping is the main process that most of the paper pulp produced over the world is generated from [9]. Basically, wood is converted into wood pulp through treating with $\mathrm{Na}_{2} \mathrm{~S} / \mathrm{NaOH}$ solution (white liquor) for several hours at a temperature range of $155-175^{\circ} \mathrm{C}$, where about $90-95 \%$ of the lignin present in the starting material is easily dissolved. Lately, a novel process has been developed to efficiently separate lignin from kraft black liquor called LignoBoost. This process differs from the ordinary single-stage lignin separation process in that instead of washing the lignin filter cake directly after filtration, it is rather dispersed in a re-slurry tank, offering a better control of the $\mathrm{pH}$ and hence minimising the hydrogen ion concentration gradients during the washing stage [10]. Major advantages of the LignoBoost process comprise high lignin yield, low ash and carbohydrates contents, low investment costs, and low operational costs [11]. It is expected that this type of lignin would result in more valueadded applications in future industrial installations and hasty capacity increase.

Another pulping process available, also producing high quantities of lignin, is the lignosulfonate/sulphite process. This process typically uses different sulphurous acid salts like sulphites and bisulphites, in which the lignin recovered contain about 4-8\% sulphur and are termed lignosulfonates, due to the sulfonate groups' presence in its structure [12]. Soda pulping is another existing pulping process, where biomass treatment made using an aqueous solution of $\mathrm{NaOH}$ or lime at temperatures of almost $\leq 160{ }^{\circ} \mathrm{C}$. The lignin recovered is named alkali lignin and it is considered to be a good source of phenolics and aromatics [13]. Organic solvents have else been adopted in wood delignification, referred to as Organosolv pulping. Although this process offers benefits like producing high-quality lignin and lowering the enzyme cost, it still lack economic justifications [14]. A new biphasic Organosolv-like process also accounting for biomass pretreatment and lignin recovery called Organocat has been improved and proposed recently [15]. In principle, it uses an aqueous solution of 2-methyltetrahydrofuran (2-MTHF) as an organic solvent and oxalic acid as a catalyst, where effective separation of the primary constituents of the compact lignocellulosic material is attained in a single step [16]. To this end, the pretreatment of lignocellulosic biomass and the detailed understanding of their composition and structure are much-needed steps in order to devise efficient biomass and lignin valorisation strategies [17].

In the present work, two types of lignin obtained from different pulping processes, namely LignoBoost lignin and alkali-treated lignin were characterised for further use in their valorisation towards producing high-value chemicals. Characterisation was performed using Brunauer-EmmettTeller (BET) to investigate the textural properties, particle size distribution (PSD) to tackle and report information about the size and range of lignin agglomerates, Fourier transform infrared spectroscopy (FT-IR) and ultravioletvisible absorption spectroscopy (UV-Vis) to analyse the chemical structure, gel permeation chromatography (GPC) for determining the molecular weight distribution, and thermogravimetric analysis (TGA) to test the thermal degradation and stability. Applications were also proposed for better valorisation strategies with a special emphasis on the biological conversion of lignin.

\section{Materials and Methods}

\section{Lignins}

Two types of commercial technical lignin, namely LignoBoost lignin and alkali-treated lignin were investigated in this study. The LignoBoost lignin was obtained from Innventia's pilot plant at Bäckhammar, Sweden, while the alkali-treated lignin with low sulfonate content (4\% of sulphur) was purchased from Sigma-Aldrich. The LignoBoost lignin is fine powder and it is composed of several heterogeneous agglomerated molecules. The powder is light brown in appearance and is completely soluble in alkaline solutions. The sulphur present in the lignin is a mixture of inorganic, elemental, and organic bonds, where in approximate terms, $30 \%$ of the sulphur is inorganic, $1 \%$ is elemental, and the rest is organic. The sulphur content in the LignoBoost kraft lignin is normally of lower value between 1 and $3 \%$, with $1.8 \%$ as a typical value of the sample studied. Besides, the lignin powder from the LignoBoost process exhibits about $30 \%$ moisture content. The commercial alkali-treated lignin, on the other hand, is a black powder in appearance, more alkaline, $\mathrm{pH} 10.5$, and contains no reducing sugars.

\section{Textural Properties}

The specific surface area and the pore size of both lignins were determined by the BET adsorption-desorption 
method using a Micromeritics ASAP 2400 instrument (Norcross, GA, USA). Pore volume analysis was performed using the Barrett-Joyner-Halenda (BJH) method [18]. Before the analysis, the lignin samples were dried over 7 days and at a degassing temperature of $115^{\circ} \mathrm{C}$, under rough vacuum. Then, the measurements were conducted through the adsorption of nitrogen, at liquid nitrogen temperature, onto the biopolymer surface at different pressures. The desorption-isotherm was employed for the analysis and the values obtained are the average of two analysis runs.

\section{Particle Size Analysis}

The size distribution of the lignin particles was measured by laser diffraction with a Sympatec HELOS laser diffractometer equipped with the RODOS dispersing unit (Sympatec GmbH, Clausthal-Zellerfeld, Germany) in dry powder form after dispersing with compressed air (3 bar). The system uses a $632.8 \mathrm{~nm} \mathrm{HeNe}$ laser for illuminating the particles and is capable of detecting particles in the dynamic size range of $0.5-875 \mu \mathrm{m}$. The lignins PSD were also characterized by the $D_{10}, D_{50}$, and $D_{90}$ values, giving estimates for the percentage undersize, as well as the volume mean diameter (VMD), the sample volume weighted mean particle size; values were calculated based on the Fraunhofer theory and analysed in the standardised WINDOX software.

\section{Spectroscopic Measurements}

Fourier transform infrared (FT-IR) spectra of the lignins were obtained on a Bruker Alpha-P Platinum FT-IR spectrometer, equipped with a platinum attenuated total reflectance (ATR) sampling module hosting a diamond crystal (single bounce). For each sample, 24 scans were recorded in the wavenumber range of $4000-400 \mathrm{~cm}^{-1}$ in the transmittance mode with a resolution of $4 \mathrm{~cm}^{-1}$.

The ultraviolet-visible (UV-Vis) absorption spectra of the lignin samples were recorded on a spectrophotometer (UV-160, Shimadzu Co., Kyoto, Japan). Following an established procedure [19], the samples were dissolved in a $0.1 \mathrm{M} \mathrm{NaOH}$ solution, diluted with deionised water, and the absorbance between 240 and $420 \mathrm{~nm}$ was measured.

\section{Molecular Weight Distribution}

The molecular weight distribution data of the lignin samples was determined by a GPC system. The system used was a Waters 600E chromatography system (Waters, Milford, MA, USA) equipped with a Waters 2414 refractive index (RI) detector, a Waters $486 \mathrm{UV}$ absorbance detector and an analytical column packed with $30 \mathrm{~cm}$ of Superdex 30 and $30 \mathrm{~cm}$ of Superdex 200 (GE Healthcare, Uppsala, Sweden). The column was operated at ambient temperature and eluted with $\mathrm{NaOH}$ (analytical grade) as the mobile phase at a flowrate of $1.0 \mathrm{~mL} / \mathrm{min}$. Calibration was performed using polyethylene glycol (PEG) standards ranging from 400 to 35,000 g/mol in the eluent (Merck Schuchardt OHG, Hohenbrunn, Germany). The two lignins were dissolved at a concentration of $1 \mathrm{mg} / \mathrm{mL}$ in the eluent. The solution was further filtered using a $0.2 \mu \mathrm{m}$ filter in order to remove any suspended matter, and $500 \mu \mathrm{L}$ from the filtered solution was finally injected into the GPC system. Due to the comparison with PEG standard, both the molecular weight and the molecular number should be considered relative.

\section{Thermogravimetric Analysis}

The thermal stability studies for the lignins were performed by TGA using a TGA Q500 (TA Instruments) thermogravimetric analyser. Lignin samples of about $5 \mathrm{mg}$ were used in both cases and placed in open alumina crucibles. Measurements were conducted in an inert atmosphere; the instrument was continuously flushed with a nitrogen flow of $60 \mathrm{~mL} / \mathrm{min}$. The thermal program consisted of an isothermal step at $150{ }^{\circ} \mathrm{C}$ for $10 \mathrm{~min}$, accompanied by a $10{ }^{\circ} \mathrm{C} / \mathrm{min}$ ramp from 25 to $600{ }^{\circ} \mathrm{C}$. The objective of the isothermal step was to eliminate moisture (hygroscopic water), as it could interfere with the degradation steps at low temperatures and initiate an oxygen-promoted lignin decomposition.

\section{Results and Discussion}

\section{Specific Surface Area and Pore Structure}

The surface area and pore size of the lignins were calculated by applying the BET analysis. Technically speaking, the lignin surface properties are affected by the biomass substrate source and the pretreatment process conditions. Table 1 summarises the results generated from the nitrogen adsorption-desorption experiments.

The adsorption and desorption information acquired from each run was used to determine the lignins specific surface area $\left(\mathrm{m}^{2} / \mathrm{g}\right)$, pore volume $\left(\mathrm{cm}^{3} / \mathrm{g}\right)$, and pore size $(\AA)$, employing the BET and BJH models. The specific surface area data are presented as BET surface area $\left(\mathrm{S}_{\mathrm{BET}}\right)$, Langmuir surface area $\left(\mathrm{S}_{\mathrm{LSA}}\right)$, BJH surface area $\left(\mathrm{S}_{\mathrm{BJH}}\right)$, and micropore area $\left(\mathrm{S}_{\text {micro }}\right)$. In addition, the single point surface areas of LignoBoost and alkali-treated lignins at $P /$ $P_{\mathrm{o}}$ of 0.21 were calculated as 0.38 and $1.20 \mathrm{~m}^{2} / \mathrm{g}$, respectively. 
Table 1 Surface area and pore structure parameters of lignins determined by BET analysis

\begin{tabular}{|c|c|c|c|c|c|c|c|c|c|}
\hline \multirow[t]{2}{*}{ Sample } & \multicolumn{4}{|c|}{ Surface area $\left(\mathrm{m}^{2} / \mathrm{g}\right)$} & \multicolumn{3}{|c|}{ Pore volume $\left(\mathrm{cm}^{3} / \mathrm{g} \times 10^{3}\right)$} & \multicolumn{2}{|c|}{ Pore size $(\AA)$} \\
\hline & $\mathrm{S}_{\mathrm{BET}}$ & $\mathrm{S}_{\mathrm{LSA}}$ & $\mathrm{S}_{\mathrm{BJH}}^{\mathrm{a}}$ & $\mathrm{S}_{\text {micro }}$ & $\mathrm{V}_{\text {total }}^{\mathrm{b}}$ & $\mathrm{V}_{\mathrm{BJH}}^{\mathrm{a}}$ & $\mathrm{V}_{\text {micro }}^{\mathrm{c}}$ & $\mathrm{D}_{\mathrm{BET}}^{\mathrm{d}}$ & $\mathrm{D}_{\mathrm{BJH}}^{\mathrm{a}}$ \\
\hline LignoBoost lignin & 0.40 & 0.54 & 0.31 & 0.26 & 1.96 & 1.87 & 0.11 & 199 & 240 \\
\hline Alkali lignin & 1.25 & 1.73 & 0.43 & 1.07 & 3.87 & 3.87 & 0.48 & 124 & 360 \\
\hline
\end{tabular}

a Calculated using the cumulative desorption data between 17 and $3000 \AA$ A diameter by the Barrett-JoynerHalenda (BJH) method

b Single point total pore volume of pores less than $3400 \AA$ in diameter at $P / P_{\mathrm{o}}=0.99$

c Micropore volume calculated by the Horvath-Kawazoe (HK) method

d Average total pore diameter (4 V/A by BET)
Fig. 2 Distribution of particle sizes for LignoBoost and alkali lignin samples

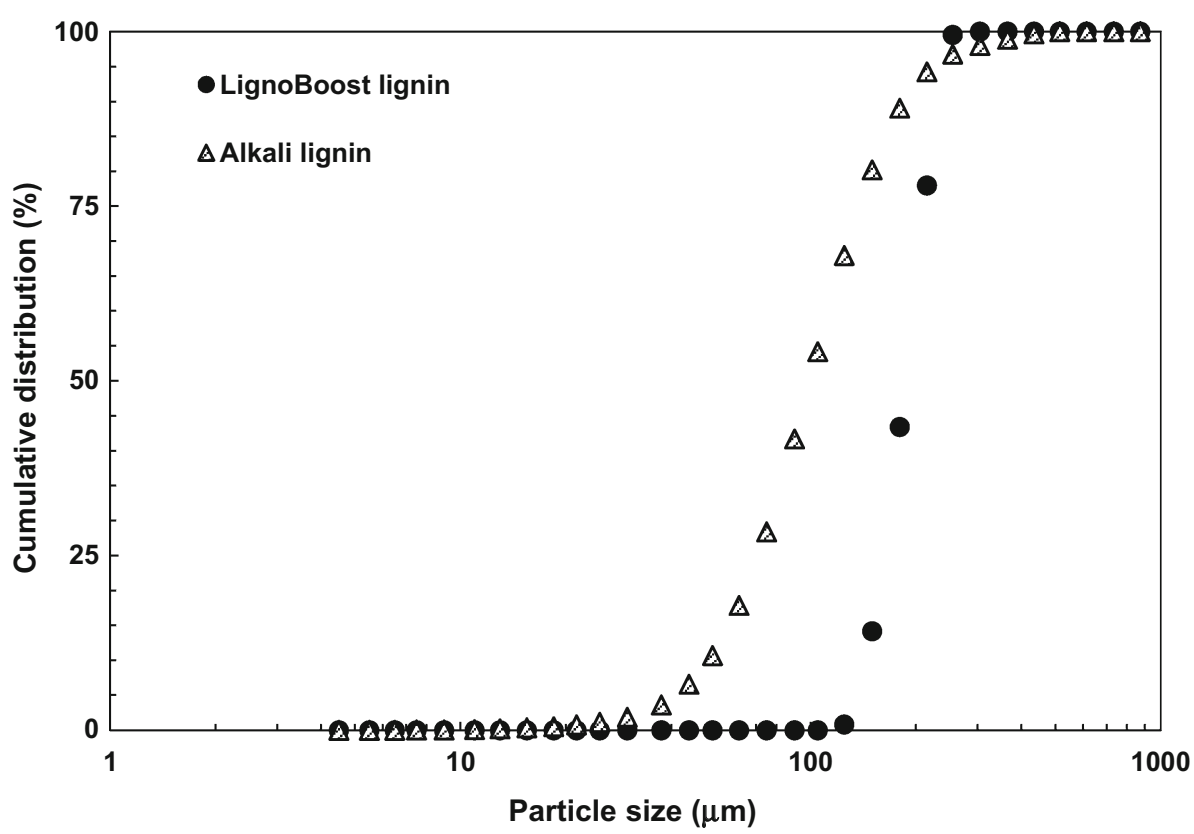

The purpose of comparing textural parameters from different pretreatment processes by this method is known to be useful [20]. Significant variations were observed with regard to the textural properties of both lignins (Table 1). Alkali-treated lignin exhibited to a higher specific surface area and pore volume than the LignoBoost lignin, suggesting an increase in the pretreatment severity of the applied process conditions for the alkali lignin. In the meanwhile, the alkali lignin BET results interestingly were comparable to another study [21]. However, to the best of the authors' knowledge, the BET parameters for LignoBoost lignin has not been previously reported.

Those results obtained suggest that alkali lignin provide a better candidate towards its biological valorisation. Within this scope, the fact that it has higher surface area and pore size would allow easier access of enzymes and microorganisms if applied to the lignin substrate. Hence, it could be biologically converted towards a wide platform of value-added chemicals via enzymatic depolymerisation and subsequent biological funnelling.

\section{Distribution of Particle Sizes}

PSD could provide information about the aggregation characteristics of lignin biomacromolecules. Figure 2 shows the cumulative PSD profiles for the two lignin samples, while the particle size characterisation data are outlined in Table 2.

The alkali lignin particles were considerably smaller than the LignoBoost lignin particles, as can be viewed in Fig. 2. It could be recognised that the pretreatment process does not result in similar size distributions of lignin macromolecules. Analysis also showed that the two lignin samples possessed a geometric PSD within the micron size range (Table 2), with VMD values of $188 \mu \mathrm{m}$ for LignoBoost lignin and $113 \mu \mathrm{m}$ for alkali lignin. It was revealed as well that the LignoBoost lignin exhibited a relatively narrower density distribution than the alkali lignin; this can be resulting from a higher degree of molecules cross-linking and aggregation. In addition, the pretreatment temperature seemed to influence the lignin 
Table 2 Particle size distribution data for the lignins used. $D_{\mathrm{x}}$ indicates that $\mathrm{x} \%$ in volume of the particles are smaller than the value stated

\begin{tabular}{lllllll}
\hline Sample & $D_{10}(\mu \mathrm{m})$ & $D_{50}(\mu \mathrm{m})$ & $D_{85}(\mu \mathrm{m})$ & $D_{90}(\mu \mathrm{m})$ & $D_{99}(\mu \mathrm{m})$ & VMD $(\mu \mathrm{m})$ \\
\hline LignoBoost lignin & 142.2 & 186.7 & 226.2 & 237.3 & 254.0 & 188.0 \\
Alkali-treated lignin & 51.2 & 100.0 & 162.8 & 186.3 & 373.3 & 113.0 \\
\hline
\end{tabular}

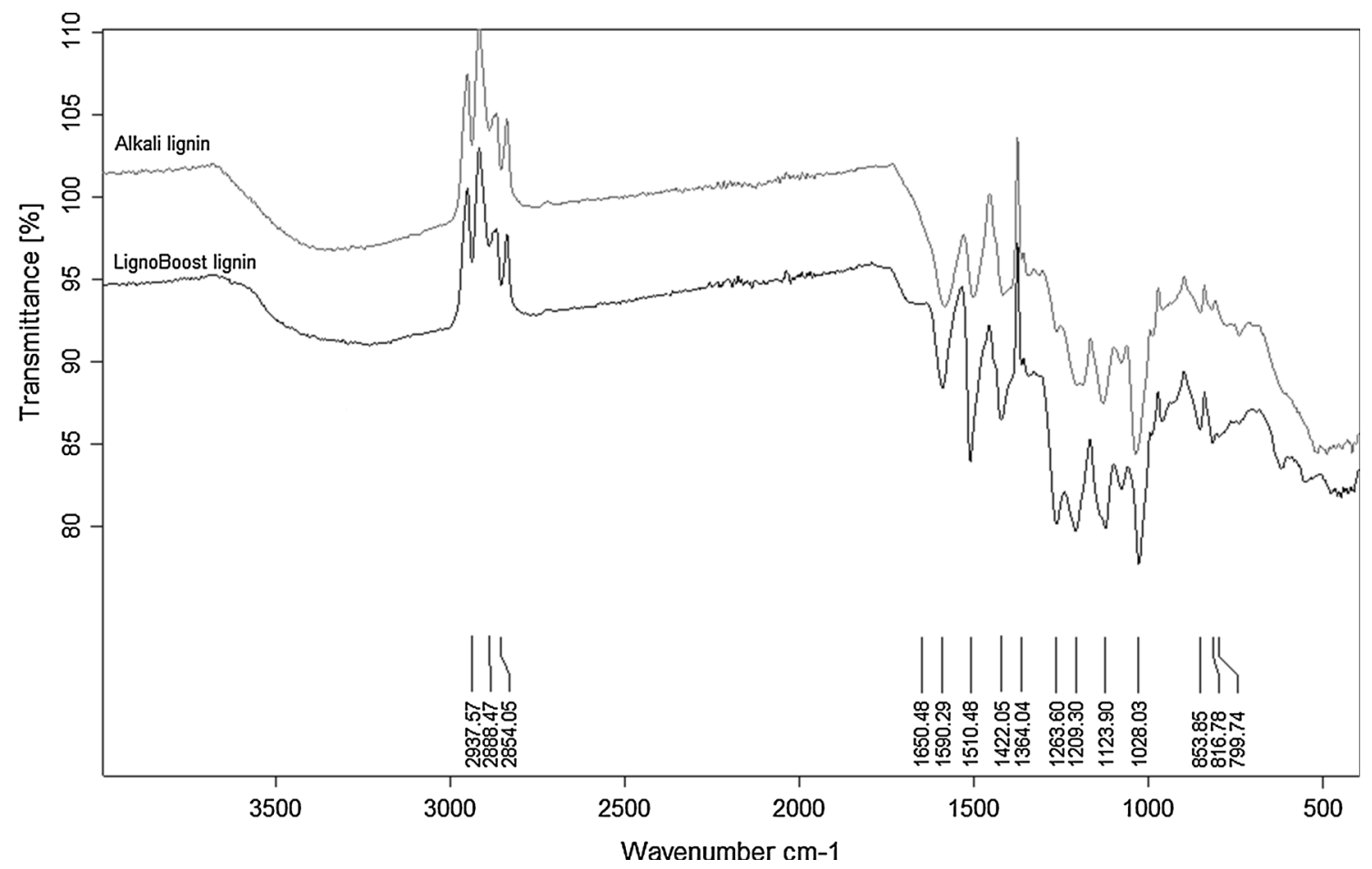

Fig. 3 FT-IR spectra of lignin samples with the wavenumber range $4000-400 \mathrm{~cm}^{-1}$

particle size, as increasing temperature might lead to decreasing particle size. Those findings support the BET results, confirming that the alkali lignin would be a better substrate for biological valorisation. The fact of constituting smaller particle sizes would make it easier to depolymerise into smaller fragments. These low molecular weight fragments would serve as better carbon sources to be further hosted by various microbial cell factories, generating further numerous forms of value-added renewable chemicals.

\section{FT-IR and UV Spectra}

Variability in lignin composition and structural changes could possibly be identified using spectrophotometric methods. This is due to the specific absorbance of the individual phenolic constituents. Figure 3 presents the FTIR spectra for both lignin samples.

As can be seen from the spectra, both lignins showed comparable behaviour, revealing the similarities of the functional groups found in them. Moreover, the corresponding bands and assignments for the two lignins are reported in Table 3. Here, we introduce an analysis of the spectra recorded for both lignins used in this study, based on the bands assignments previously reported in literature findings $[22,23]$.

Both lignins showed bands at 1600, 1515, and $1425 \mathrm{~cm}^{-1}$ that are corresponding to aromatic ring vibrations of the phenylpropane $\left(\mathrm{C}_{9}\right)$ skeleton, exhibiting the typical lignin absorption bands. In the wide absorption range between 3600 and $3000 \mathrm{~cm}^{-1}$, similar bands appeared for the two lignins, which can be attributed to the hydroxyl groups in aromatic and aliphatic structures. The absorption band peaks at $2938 \mathrm{~cm}^{-1}$ for both lignins mainly corresponds to the $\mathrm{C}-\mathrm{H}$ stretching in the methyl and methylene groups of the side chains, while the bands at $2854 \mathrm{~cm}^{-1}$ can be arising from the $\mathrm{C}-\mathrm{H}$ stretching in the aromatic methoxyl groups. No bands were found for both lignins within the range between 1715 and $1705 \mathrm{~cm}^{-1}$ that originates from the unconjugated carbonyl-carboxyl stretching. The absence of such bands was found in agreement with previous work [24]. However, a strong band shoulder appeared at $1650 \mathrm{~cm}^{-1}$ for the LignoBoost lignin corresponding to the conjugated carbonyl-carboxyl 
Table 3 FT-IR bands and assignments for LignoBoost and alkali lignins

\begin{tabular}{|c|c|c|c|c|}
\hline \multirow[t]{2}{*}{ Band $\left(\mathrm{cm}^{-1}\right)$} & \multirow[t]{2}{*}{ Vibration } & \multirow[t]{2}{*}{ Assignment } & \multicolumn{2}{|c|}{ Band location $\left(\mathrm{cm}^{-1}\right)$} \\
\hline & & & LignoBoost & Alkali \\
\hline $2960-2925$ & $\mathrm{C}-\mathrm{H}$ stretching & $\mathrm{CH}_{3}+\mathrm{CH}_{2}$ & 2938 & 2938 \\
\hline $2850-2840$ & $\mathrm{C}-\mathrm{H}$ stretching & $\mathrm{OCH}_{3}$ & 2854 & 2854 \\
\hline 1650 & $\mathrm{C}=\mathrm{O}$ stretching & Conjugated $\mathrm{C}=\mathrm{O}$ & 1650 & - \\
\hline 1600 & $\mathrm{C}-\mathrm{C}$ stretching & Aromatic skeleton & 1590 & 1585 \\
\hline 1515 & $\mathrm{C}-\mathrm{C}$ stretching & Aromatic skeleton & 1510 & 1501 \\
\hline 1425 & $\mathrm{C}-\mathrm{C}$ stretching & Aromatic skeleton & 1422 & 1417 \\
\hline 1365 & $\mathrm{O}-\mathrm{H}$ in-plane deformation & Phenolic $\mathrm{OH}$ & 1364 & 1364 \\
\hline 1270 & $\mathrm{C}-\mathrm{O}$ stretching & G & 1264 & - \\
\hline 1220 & $\mathrm{C}-\mathrm{O}(\mathrm{H})+\mathrm{C}-\mathrm{O}(\mathrm{Ar})$ stretching & Phenolic $\mathrm{OH}+$ ether & 1209 & 1189 \\
\hline 1125 & $\mathrm{Ar}-\mathrm{CH}$ in-plane deformation & G & 1124 & 1131 \\
\hline 1030 & $\mathrm{C}-\mathrm{O}(\mathrm{H})+\mathrm{C}-\mathrm{O}(\mathrm{C})$ stretching & First order aliphatic $\mathrm{OH}+$ ether & 1028 & 1037 \\
\hline 855 & $\mathrm{Ar}-\mathrm{CH}$ out-of-plane deformation & G & 854 & 854 \\
\hline 810 & $\mathrm{Ar}-\mathrm{CH}$ out-of-plane deformation & G & 817 & 819 \\
\hline
\end{tabular}

stretching. This was not the case in that of the alkali-treated lignin, which can be due to the presence of more associated water or protein impurity. Considerable amounts of residual minerals is also expected to be present and they remain in the lignin fraction after pretreatment process. The analysis difficulty starts to increase below the $1400 \mathrm{~cm}^{-1}$ region because of the complex bands contributing from various modes of vibration. In spite of that, this spectral region constitutes specific vibrations to the monolignol precursors, allowing better lignin structural characterisation. The weak bands appearing at $1364 \mathrm{~cm}^{-1}$ for both samples can be originated from non-etherified phenolic $\mathrm{OH}$ groups, which is liberated from the cleavage of $\beta-O-4$ and $\alpha-O-4$ linkages during the cooking process; this supports extensive phenol ether cleavage during pulping. The characteristic syringyl (S) bands for both lignins were not found, due to vanishing of the bands at 1326, 1115, and $825 \mathrm{~cm}^{-1}$. Conversely, both samples revealed the characteristic vibrations of the guaiacyl $(\mathrm{G})$ unit at around 1125 , 855 , and $810 \mathrm{~cm}^{-1}$, but with different intensities, confirming that both lignins incorporated potential active sites towards polymerisation. More considerations should be taken into account regarding this point in the scope of better valorisation routes. For instance, incorporating mediators during enzymatic depolymerisation/biochemical pathway or capping agents throughout the chemical pathway.

UV spectroscopy was also adopted to monitor the lignins distribution variability and purity. Figure 4 shows the UV absorption spectra of both the LignoBoost and alkalitreated lignin samples.

No significant difference was noted within the acquired UV spectra for both lignin samples. It was found that both lignins exhibited an absorption maxima at around $\lambda$ $280 \mathrm{~nm}$, which is quite common for technical lignins, originating from the aromatic rings/non-conjugated phenolic groups present in the lignins structure and executed priory within the FT-IR spectra. However, LignoBoost lignin revealed a slightly higher absorbance strength than alkali lignin due to conducting the measurements in an alkaline medium [23]. It is also worth mentioning that absorption strength of both lignins were considered to be high for the visible solar wavelength range, which can be regarded to their deep/dark colours.

\section{Molecular Weight}

The molecular weight of lignin is a fundamental property that affects the biomass recalcitrance and lignin valorisation, where the most common characterisation technique employed in its measurement is the GPC [25]. Besides, the GPC technique has proven earlier to be reliable in determining the molecular weight distribution of kraft lignin and alkali lignin [26]. The GPC analysis using PEG standards and $\mathrm{NaOH}$ as eluent was performed to follow the molecular weight distribution of LignoBoost lignin and alkali-treated lignin samples. Figure 5 shows the gel permeation chromatograms for the lignin samples with a characteristic UV absorption measured at $280 \mathrm{~nm}$.

Apparently, both lignin samples manifested different normalised GPC elution profiles. Alkali lignin exhibited higher molecular weight distribution values than the LignoBoost lignin. This can be attributed to the promotion of repolymerisation reactions during soda pulping process affecting the lignin molecular weight [22]. To give an instance, under the alkaline conditions, alkali- 
Fig. 4 UV-Vis absorption spectra of lignin samples under UV light
Fig. 5 Gel permeation chromatogram for LignoBoost and alkali lignin samples with characteristic UV absorption at $280 \mathrm{~nm}$. The arrows indicate the molecular weight $(\mathrm{Da})$ of the PEG standards that were used for calibration
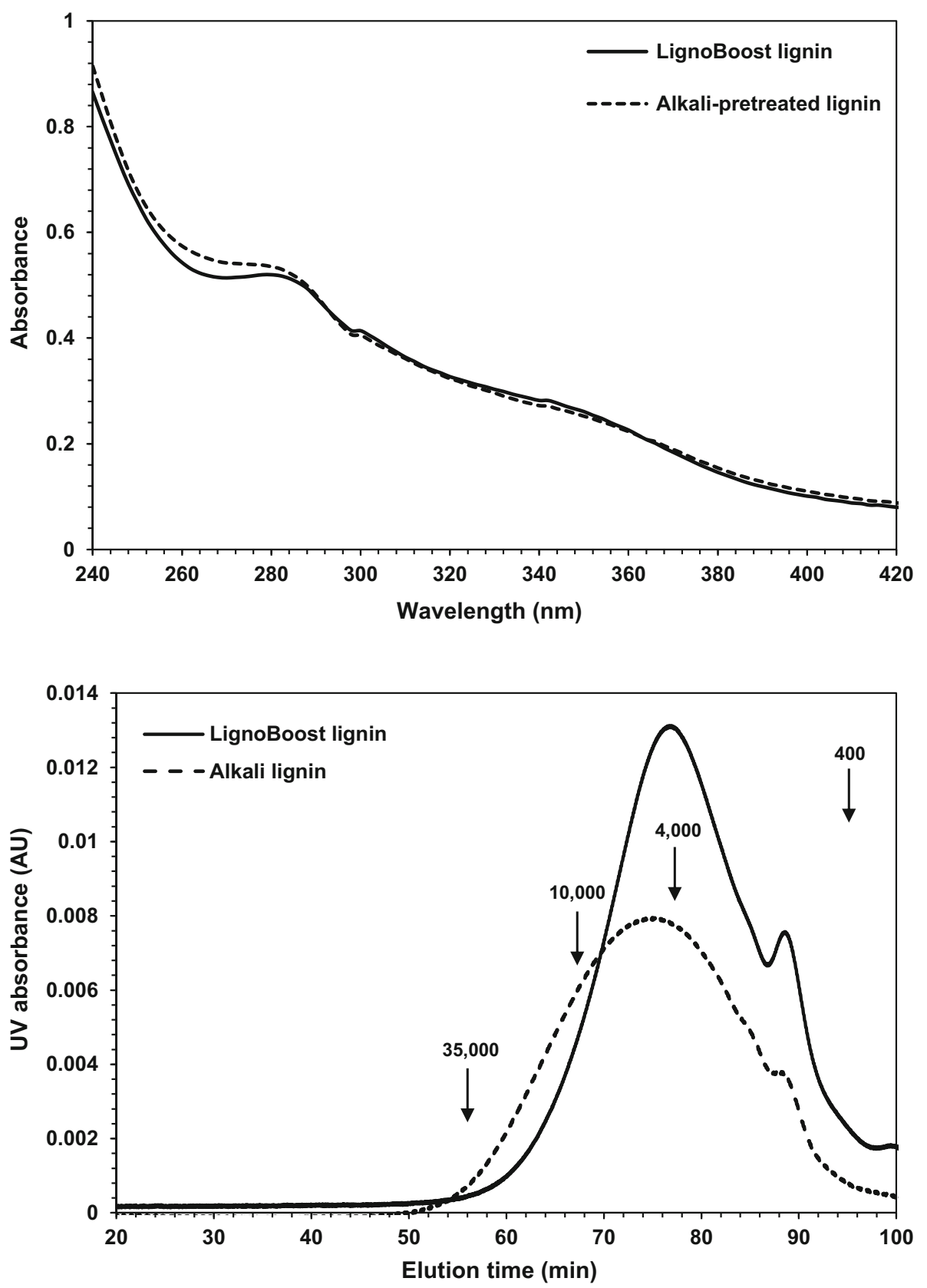

stable methylene linkages are produced through the reaction of quinone methide intermediates (formed from $\alpha$ hydroxyl groups) with other lignin fragments, leading to higher molecular weight distribution values.

From this perspective, it can be deduced that the LignoBoost lignin could be more readily depolymerised, whatever the pathway, than the alkali lignin owing to its lower molecular weight values. Although the BET analysis showed that the alkali lignin provided a better candidate for the biological conversion, here, the contrast occurred due to easier transformations and valorisation of low molecular weight lignin rather than high molecular weight ones.

\section{Thermal Stability}

Thermogravimetric analysis was conducted in order to compare the thermal stability of the lignin samples and the acquired characteristic results are given in Table 4. Furthermore, the thermogravimetric (TG) and first derivative thermogravimetric (DTG) curves are depicted in Fig. 6a, b, respectively.

TG curves represent the weight loss of lignin samples with respect to the thermal degradation temperature. Withal, the first derivative of the aforementioned curve (DTG) indicates the weight loss corresponding rate, where 
Table 4 Thermal stability characteristics of lignin samples

\begin{tabular}{lllc}
\hline Sample & $\begin{array}{l}\text { Temperature of } 40 \% \\
\text { weight loss }\left({ }^{\circ} \mathrm{C}\right)\end{array}$ & $\mathrm{DTG}_{\max }\left({ }^{\circ} \mathrm{C}\right)$ & Residue (\%) \\
\hline LignoBoost lignin & 410 & 327 & 48 \\
Alkali-treated lignin & 488 & 307 & 57 \\
\hline
\end{tabular}

Fig. 6 TG curves (a) and DTG curves (b) for LignoBoost lignin and alkali-pretreated lignin
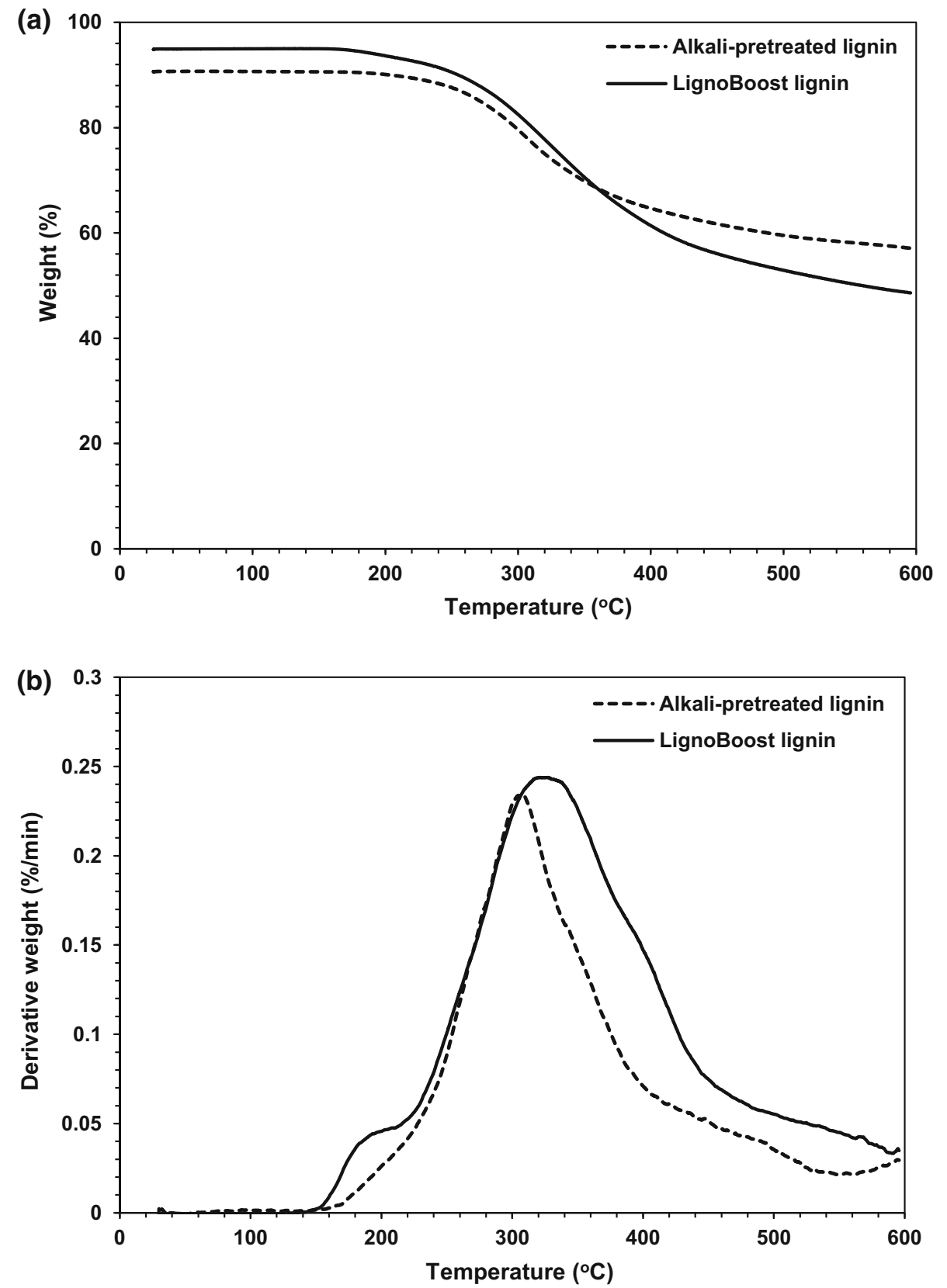

the peak of this curve $\left(\mathrm{DTG}_{\max }\right)$ expresses the single decomposition temperature and can be used to demonstrate and compare the thermal stability characteristics of tested materials.

It can be noted that the thermal degradation of both lignin samples spans a wide range of temperature between 225 and $600{ }^{\circ} \mathrm{C}$. At $40 \%$ weight loss, the decomposition temperatures were estimated to be 410 and $488{ }^{\circ} \mathrm{C}$ for LignoBoost lignin and alkali-treated lignin, respectively. Nonetheless, the temperatures corresponding to the maximum rate of weight loss for LignoBoost lignin and alkali lignin appeared to be 327 
and $307{ }^{\circ} \mathrm{C}$, respectively. The $\mathrm{DTG}_{\max }$ value of the alkali lignin is thus slightly lower than that of the LignoBoost lignin which may be attributed to different $\mathrm{C}-\mathrm{C}$ linkages content of both lignins, though we found it in agreement with that value reported by Nadji et al. [27]. At $600{ }^{\circ} \mathrm{C}$, the amounts of non-volatile residue were determined to be 48 and $57 \%$ for LignoBoost and alkali lignins, respectively. These amounts of residue were incompletely burned and existed in the solid form, revealing the significant thermal stability properties of both lignins at high temperature and this could be allotted to the high degree of branching and the extremely condensed aromatic structures formation. This tendency could be accounted for, as the higher the lignin is condensed and complex, the more easily it is converted to charcoal owing to its great structural similarity [28]. Referring that both lignin samples come from two alkaline pulping processes, such alkaline conditions lead to the breakdown of protolignin, lignin fragments dissolution, and later subsequent recondensation. Also, at this point, the higher cross-linking capacity of alkali lignin at $600{ }^{\circ} \mathrm{C}$ can be observed, displaying the higher $\mathrm{H}$ structures content comparing to the LignoBoost sample.

For the sake of application purposes, these results show the potential of both lignins valorisation towards producing bio-oil [29] or biomaterials [30], for example, and biological conversion due to application at mild conditions. In contrast, they do not provide good candidates for phenolformaldehyde resin synthesis, as the maximum rate loss within the nonmodified resins appears at $345^{\circ} \mathrm{C}$ [22] or other adhesives [31].

\section{Conclusions}

Lignin is a key compound and the development of valueadded products from it would greatly boost the economics of future biorefineries, highlighting the importance of understanding its complex nature. In this context, the physicochemical characterisation of two technical lignin samples from different pulping processes has been performed. Results have shown the notable influence of the pretreatment severity on the lignin chemical composition and functional properties. The insights gained in the technical lignins structure and properties helped in proposing better valorisation strategies. Potential applications have been finally suggested for both lignins with a particular focus on their depolymerisation and biological valorisation.

Acknowledgments This research is supported by the Swedish Foundation for Strategic Research (SSF), Grant RBP14-0052.
Open Access This article is distributed under the terms of the Creative Commons Attribution 4.0 International License (http://crea tivecommons.org/licenses/by/4.0/), which permits unrestricted use, distribution, and reproduction in any medium, provided you give appropriate credit to the original author(s) and the source, provide a link to the Creative Commons license, and indicate if changes were made.

\section{References}

1. Ragauskas, A.J., Beckham, G.T., Biddy, M.J., Chandra, R., Chen, F., Davis, M.F., Davison, B.H., Dixon, R.A., Gilna, P., Keller, M., Langan, P., Naskar, A.K., Saddler, J.N., Tschaplinski, T.J., Tuskan, G.A., Wyman, C.E.: Lignin valorization: improving lignin processing in the biorefinery. Science 344, 1246843 (2014)

2. Gosselink, R.J.A., Teunissen, W., van Dam, J.E.G., de Jong, E., Gellerstedt, G., Scott, E.L., Sanders, J.P.M.: Lignin depolymerisation in supercritical carbon dioxide/acetone/water fluid for the production of aromatic chemicals. Bioresour. Technol. 106, 173-177 (2012)

3. Azadi, P., Inderwildi, O.R., Farnood, R., King, D.A.: Liquid fuels, hydrogen and chemicals from lignin: a critical review. Renew. Sustain. Energy Rev. 21, 506-523 (2013)

4. Tunå, P., Hulteberg, C.: Woody biomass-based transportation fuels: a comparative techno-economic study. Fuel 117, 1020-1026 (2014)

5. Boeriu, C.G., Fiţigău, F.I., Gosselink, R.J.A., Frissen, A.E., Stoutjesdijk, J., Peter, F.: Fractionation of five technical lignins by selective extraction in green solvents and characterisation of isolated fractions. Ind. Crops Prod. 62, 481-490 (2014)

6. Huber, G.W., Iborra, S., Corma, A.: Synthesis of transportation fuels from biomass: chemistry, catalysts, and engineering. Chem. Rev. 106, 4044-4098 (2006)

7. Chakar, F.S., Ragauskas, A.J.: Review of current and future softwood kraft lignin process chemistry. Ind. Crops Prod. 20, 131-141 (2004)

8. Sjöström, E.: Wood Chemistry: Fundamentals and Applications. Academic Press, San Diego (1993)

9. Moshkelani, M., Marinova, M., Perrier, M., Paris, J.: The forest biorefinery and its implementation in the pulp and paper industry: energy overview. Appl. Therm. Eng. 50, 1427-1436 (2013)

10. Öhman, F., Theliander, H., Tomani, P., Axegard, P.: Method for separating lignin from black liquor, US patent 8486224 to Lignoboost AB (2013)

11. Tomani, P.: The LignoBoost process. Cellul. Chem. Technol. 44, 53-58 (2010)

12. Calvo-Flores, F.G., Dobado, J.A., Isac-García, J., Martín-Martínez, F.J.: Lignin and Lignans as Renewable Raw Materials: Chemistry, Technology and Applications. Wiley, Chichester (2015)

13. Guo, D.L., Yuan, H.Y., Yin, X.L., Wu, C.Z., Wu, S.B., Zhou, Z.Q.: Effects of chemical form of sodium on the product characteristics of alkali lignin pyrolysis. Bioresour. Technol. 152, 147-153 (2014)

14. Hergert, H.L.: Developments in organosolv pulping: an overview. In: Young, R.A., Akhtar, M. (eds.) Environmentally Friendly Technologies for the Pulp and Paper Industry. Wiley, New York (1998)

15. Abdelaziz, O.Y., Gadalla, M.A., El-Halwagi, M.M., Ashour, F.H.: A hierarchical approach for the design improvements of an Organocat biorefinery. Bioresour. Technol. 181, 321-329 (2015)

16. vom Stein, T., Grande, P.M., Kayser, H., Sibilla, F., Leitner, W., Domínguez de María, P.: From biomass to feedstock one-step 
fractionation of lignocellulose components by the selective organic acid-catalyzed depolymerization of hemicellulose in a biphasic system. Green Chem. 13, 1772-1777 (2011)

17. Kalogiannis, K.G., Stefanidis, S., Marianou, A., Michailof, C., Kalogianni, A., Lappas, A.: Lignocellulosic biomass fractionation as a pretreatment step for production of fuels and green chemicals. Waste Biomass Valoriz. 6, 781-790 (2015)

18. Barrett, E.P., Joyner, L.G., Halenda, P.P.: The determination of pore volume and area distributions in porous substances. I: computations from nitrogen isotherms. J. Am. Chem. Soc. 73, 373-380 (1951)

19. Bu, L., Tang, Y., Gao, Y., Jian, H., Jiang, J.: Comparative characterization of milled wood lignin from furfural residues and corncob. Chem. Eng. J. 175, 176-184 (2011)

20. Piccolo, C., Wiman, M., Bezzo, F., Lidén, G.: Enzyme adsorption on $\mathrm{SO}_{2}$ catalyzed steam-pretreated wheat and spruce material. Enzyme Microb. Technol. 46, 159-169 (2010)

21. Pareek, N., Gillgren, T., Jönsson, L.J.: Adsorption of proteins involved in hydrolysis of lignocellulose on lignins and hemicelluloses. Bioresour. Technol. 148, 70-77 (2013)

22. Tejado, A., Peña, C., Labidi, J., Echeverria, J.M., Mondragon, I.: Physico-chemical characterization of lignins from different sources for use in phenol-formaldehyde resin synthesis. Bioresour. Technol. 98, 1655-1663 (2007)

23. Ibrahim, M.N.M., Zakaria, N., Sipaut, C.S., Sulaiman, O., Hashim, R.: Chemical and thermal properties of lignins from oil palm biomass as a substitute for phenol in a phenol formaldehyde resin production. Carbohydr. Polym. 86, 112-119 (2011)

24. Boeriu, C.G., Bravo, D., Gosselink, R.J.A., van Dam, J.E.G.: Characterisation of structure-dependent functional properties of lignin with infrared spectroscopy. Ind. Crops Prod. 20, 205-218 (2004)

25. Tolbert, A., Akinosho, H., Khunsupat, R., Naskar, A.K., Ragauskas, A.J.: Characterization and analysis of the molecular weight of lignin for biorefining studies. Biofuels Bioprod. Biorefining 8, 836-856 (2014)

26. Chen, F., Li, J.: Aqueous gel permeation chromatographic methods for technical lignins. J. Wood Chem. Technol. 20, 265-276 (2000)

27. Nadji, H., Diouf, P.N., Benaboura, A., Bedard, Y., Riedl, B., Stevanovic, T.: Comparative study of lignins isolated from Alfa grass (Stipa tenacissima L.). Bioresour. Technol. 100, 3585-3592 (2009)

28. Kim, J.-Y., Oh, S., Hwang, H., Kim, U.-J., Choi, J.W.: Structural features and thermal degradation properties of various lignin macromolecules obtained from poplar wood (Populus albaglandulosa). Polym. Degrad. Stab. 98, 1671-1678 (2013)

29. Hua, W., Liu, C., Wu, S., Li, X.: Analysis of structural units and their influence on thermal degradation of alkali lignins. BioResources 11, 1959-1970 (2016)

30. Monteil-Rivera, F., Phuong, M., Ye, M., Halasz, A., Hawari, J.: Isolation and characterization of herbaceous lignins for applications in biomaterials. Ind. Crops Prod. 41, 356-364 (2013)

31. El Mansouri, N.-E., Salvadó, J.: Structural characterization of technical lignins for the production of adhesives: application to lignosulfonate, kraft, soda-anthraquinone, organosolv and ethanol process lignins. Ind. Crops Prod. 24, 8-16 (2006) 